\title{
PERIPHERAL PLASMA PROGESTERONE LEVELS DURING THE BOVINE OESTROUS CYCLE
}

\author{
G. H. STABENFELDT, L. L. EWING AND L. E. MaDONALD \\ Department of Physiology and Pharmacology, Oklahoma State University, Stillwater, \\ Oklahoma, U.S.A. \\ (Received 2nd Fuly 1968)
}

\begin{abstract}
Summary. Progesterone was determined daily in the peripheral plasma of six cows for a total of seven complete oestrous cycles. Progesterone levels ranged from less than $0.5 \mathrm{ng} / \mathrm{ml}$ plasma during the follicular phase to $6.6 \mathrm{ng} / \mathrm{ml}$ plasma $(6 \cdot 1$ to $10.2 \mathrm{ng}$ ) at peak luteal phase. Progesterone levels in cows with 21-day cycles increased rapidly from Day 3 to Day 8 (oestrus = 1) with a much slower rate of increase from Day 8 to Day 17. These cows showed a progesterone decrease of more than $50 \%$ from the previous day on Days 18 (two cows), 19 (one cow) and 21 (two cows). Two other cows with cycles of 22 and 23 days' duration both had a similar decline on Day 20.

A variable time interval of 1 to 5 days was observed between the decline of progesterone and the occurrence of oestrus. These data indicate that considerable variation may exist among cows as to time requirements for follicle development and maturation.

Monitoring of peripheral levels of progesterone is suggested as a means of studying corpus luteum function.
\end{abstract}

\section{INTRODUCTION}

Several recent reports (Plotka, Erb, Gallahan \& Gomes, 1967; Schomberg, Coudert \& Short, 1967; Gupta \& Pope, 1968) have indicated a correlation between peripheral plasma progesterone levels and corpus luteum function in the cow during the oestrous cycle. Such studies were difficult before the advent of gas-liquid chromatography (GLC) and double isotope derivative methods because of the large volume of bovine plasma $(400$ to $500 \mathrm{ml}$ ) required for analysis by u.v. spectrophotometry. The need to monitor progesterone levels daily in the peripheral blood of pregnant cows in the immediate pre-partum period led to the adaptation of a technique (van der Molen \& Groen, 1965) which utilized GLC of a chloroacetate derivative of progesterone; this allowed progesterone to be determined in $20 \mathrm{ml}$ of peripheral plasma regardless of the stage of pregnancy or oestrous cycle. This approach has allowed a daily study of corpus luteum (CL) function to be made in individual cyclic cows based on levels of progesterone in peripheral plasma. Preliminary results using this technique in the cow have been reported (Stabenfeldt, Ewing \& McDonald, 1966; Stabenfeldt, 1968b). 


\section{MATERIALS AND METHODS}

Animals and collection of blood

The animals used in this study were multiparous Friesian cows (one animal was a Friesian-shorthorn crossbred). All animals had normal breeding histories including at least two lactations. Three of the cows (Nos. 07, 24 and 40) had not lactated for about 1 year, while the others (Nos. 11, 17 and 46) were lactating at the start of the experiment but were not milked subsequently. The animals were housed in a large paddock and fed a ration of alfalfa and milo (grain sorghum). Sexual behaviour was used to assess the onset of psychic oestrus which was designated Day 1 of the oestrous cycle. Blood was obtained from the jugular vein of five cows (Nos. 07, 11, 17, 24 and 46) daily between 08.00 and 10.00 hours starting on 13th April 1967, regardless of the stage of cycle, until data had been collected for one complete oestrous cycle. Blood was obtained from No. 40 for 45 consecutive days or through two complete cycles. One hundred $\mathrm{ml}$ of blood were obtained daily using $1 \mathrm{ml}$ potassium oxalate $(10 \%$ solution) $/ 9 \mathrm{ml}$ blood. The cows were restrained by the use of a head stanchion for the collection of blood. Blood volume was measured and duplicate haematocrit values were determined with an International microcapillary centrifuge, Model MB. Plasma was separated in a refrigerated centrifuge at $7200 \mathrm{~g}$ for $20 \mathrm{~min}$ at $0^{\circ} \mathrm{C}$. The bleeding regimen had no adverse effect on the cows as judged by haematocrit values, physical condition and occurrence of oestrus.

\section{Analysis of progesterone}

The method used to quantitate progesterone has been reported (Stabenfeldt, Ewing, Patton \& McDonald, 1969). It is a modification of a method originally devised by van der Molen \& Groen (1965) involving the following steps:

1. Addition of an internal isotope standard and extraction of progesterone from plasma with dichloromethane.

2. Saponification of solvent residue.

3. Isolation of progesterone by thin layer chromatography (TLC).

4. Enzymatic conversion of progesterone to 20 $\beta$-hydroxypregn-4-en-3-one.

5. Acetylation of 20 $\beta$-hydroxypregn-4-en-3-one with monochloroacetic anhydride.

6. Isolation of $20 \beta$-hydroxypregn-4-en-3-one monochloroacetate by TLC.

7. Quantitation by GLC with electron capture detection and liquid scintillation spectrometry.

The plasma samples were extracted and the residue saponified and washed on the same day as the samples were collected; the washed residues were stored in benzene before TLC. Of 150 plasma samples assayed, 136 were done in duplicate while one determination was made on fourteen samples, giving a total of 286 determinations.

The use of dichloromethane as the solvent and saponification of the solvent extracts rather than plasma were the critical steps that allowed the recovery of about $85 \%$ of the hormone after extraction, saponification, water washing and isolation by TLC. The acetylation reaction was the most vulnerable portion of the technique; the presence of water in the acetylation reagents had a 
marked adverse effect on recovery rates. Conversely, the drying of the acetylation reagents alone was usually sufficient to increase recovery rates substantially.

$\left[7-{ }^{3} \mathrm{H}\right]$ Progesterone was added to the plasma samples before extraction; aliquots were obtained before GLC to estimate progesterone loss to this point. The use of testosterone chloroacetate as an internal standard (Horning, Maddock, Anthony \& VandenHeuvel, 1963) allowed estimation of losses incurred during GLC. The mass of the $\left[{ }^{7-}{ }^{3} \mathrm{H}\right]$ progesterone added to the plasma was approximately $0.2 \mathrm{ng}$; this mass did not produce a peak on GLC when water blanks were taken through the method.

GLG of the chloroacetate derivative of progesterone was done with a BarberColman gas chromatograph (Selecta series 5000) equipped with an electron capture detector (Model 5120, tritium foil). Standard curves for $20 \beta$-hydroxypregn-4-en-3-one chloroacetate and testosterone chloroacetate were determined each day of data collection. The requirement that the standard curves be linear as well as pass through zero of the abscissa and ordinate was adhered to very rigidly. Since the collection of this data, the replacement of tritium with ${ }^{63} \mathrm{Ni}$ has allowed longer intervals between cleaning of the detector and thus has increased considerably the number of samples that can be analysed by the gas chromatograph each month.

A Fortran IV computer programme was used for simplified handling of the data (Stabenfeldt, 1968a).

Identification of progesterone was demonstrated by the establishment of a constant specific activity of 20 $\beta$-hydroxypregn-4-en-3-one chloroacetate following development in five different TLC systems. The molecular weight of the compound was determined as 392 (theoretical, 392) by the use of a mass spectrometer-gas chromatograph (Stabenfeldt et al., 1969).

\section{RESULTS}

Data for seven oestrous cycles in six cows were obtained (Table 1). Five cycles were of 21-day duration while the other two were 22 and 23 days in

TABLE 1

SUMMARY OF DATA ON GOWS USED IN PROGESTERONE EXPERIMENT

\begin{tabular}{c|c|c|c}
\hline $\begin{array}{c}\text { Cow } \\
\text { no. }\end{array}$ & $\begin{array}{c}\text { Cycle length } \\
\text { (days) }\end{array}$ & $\begin{array}{c}\text { Peak plasma progesterone } \\
\text { (ng/ml plasma)/day of cycle }\end{array}$ & $\begin{array}{c}\text { Day of plasma } \\
\text { progesterone decline }\end{array}$ \\
\hline 07 & 21 & $6 \cdot 7 / 11$ & 18 \\
11 & 21 & $9 \cdot 8 / 20$ & 21 \\
17 & 21 & $8 \cdot 9 / 15$ & 19 \\
24 & 21 & $10 \cdot 2 / 16$ & 18 \\
40 & 21 & $6 \cdot 1 / 13$ & 21 \\
& 22 & $7 \cdot 6 / 17$ & 21 \\
46 & 23 & $10 \cdot 2 / 14$ & 20 \\
\hline
\end{tabular}

length. The data were combined in several ways to show: (1) all seven cycles regardless of cycle length, (2) cycles of 21 days duration, and (3) cycles of 21 days duration arranged to illustrate the sharp decline in progesterone that occurred toward the end of the cycle. 
The composite data for all cycles (Text-fig. 1) show that progesterone levels varied from $0.4 \mathrm{ng} / \mathrm{ml}$ plasma at oestrus to approximately $7 \mathrm{ng} / \mathrm{ml}$ plasma (range of 6.1 to $10.2 \mathrm{ng}$ ) at peak luteal function. The decline noted on Day 18 continued until the next oestrous cycle; the first significant increase in the next cycle occurred on Day 4.

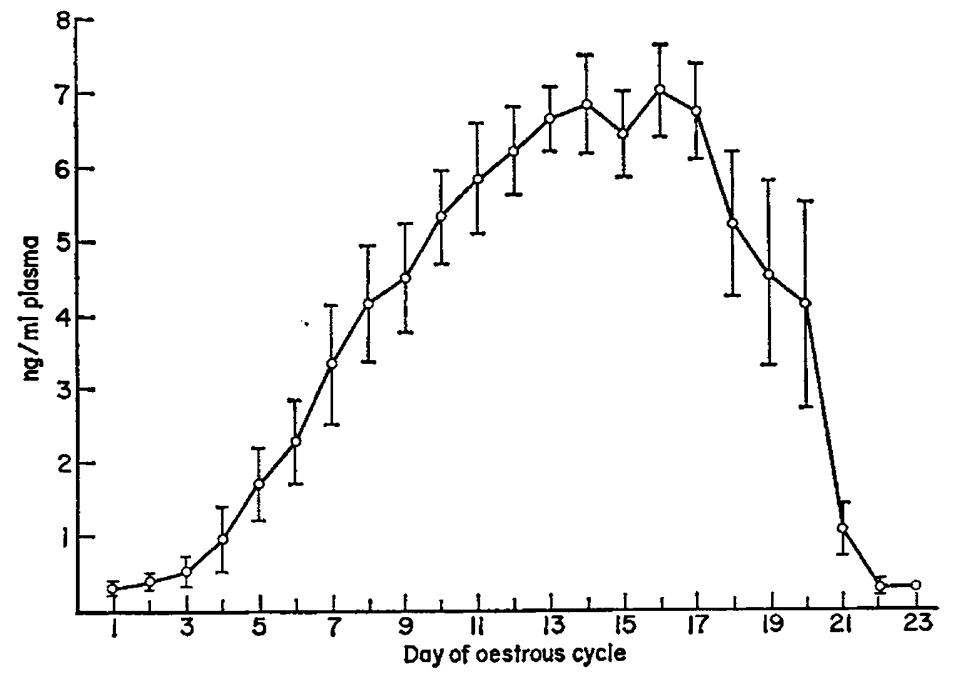

Text-Fig. 1. Progesterone concentration in jugular venous plasma during the bovine oestrous cycle (oestrus = Day 1). The data represents the composite of seven cycles (six cows) with a duration of 21 days (five), 22 days (one) and 23 days (one). Vertical bars represent the SEM.

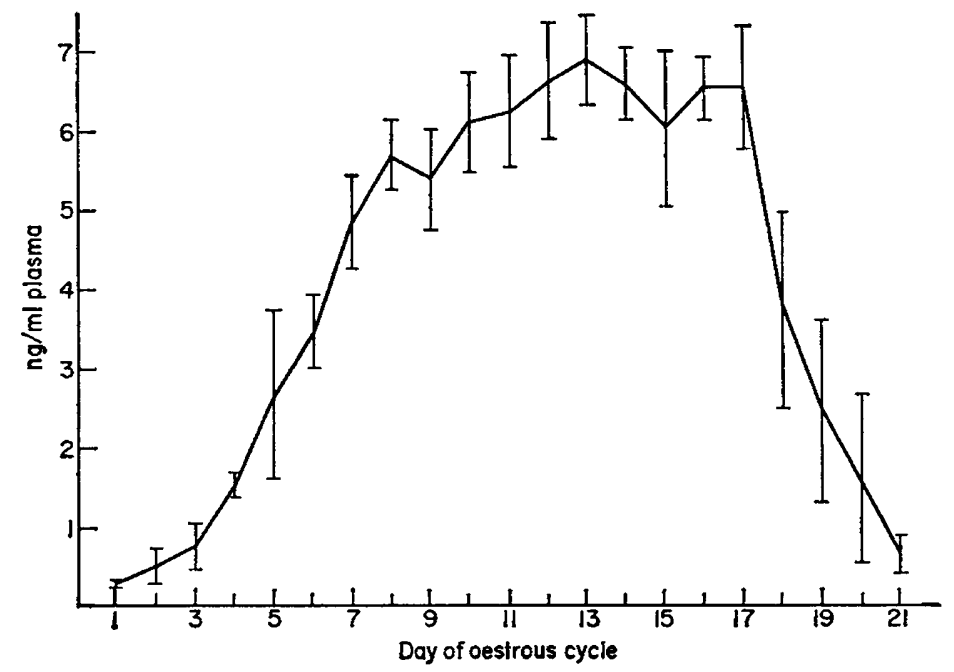

Text-Fig. 2. Progesterone concentration in jugular venous plasma from four cows with 21-day oestrous cycles (oestrus = Day 1). Vertical bars represent the SEM.

Data were combined from four cows with 21-day cycles in an attempt to present a more accurate description of the typical cow by eliminating some of the variation seen towards the end of the cycle (Text-fig. 2). Progesterone 
levels increased rapidly from Day 3 to Day 8 with a much slower rate of increase from Day 8 to Day 17. The large standard error of the mean (SEM) values recorded at Day 5 are a reflection of the variation of initial cL development that occurred following ovulation. It is again evident from SEM values that the progesterone levels for Days 18 to 20 were extremely variable. This resulted from the fact that progesterone decreased more than $50 \%$ from the previous day on Day 18 in two cows, on Day 19 in one cow and on Day 21 in the remaining cow. This demonstrates individual variations between cows as to time of cessation of CL function.

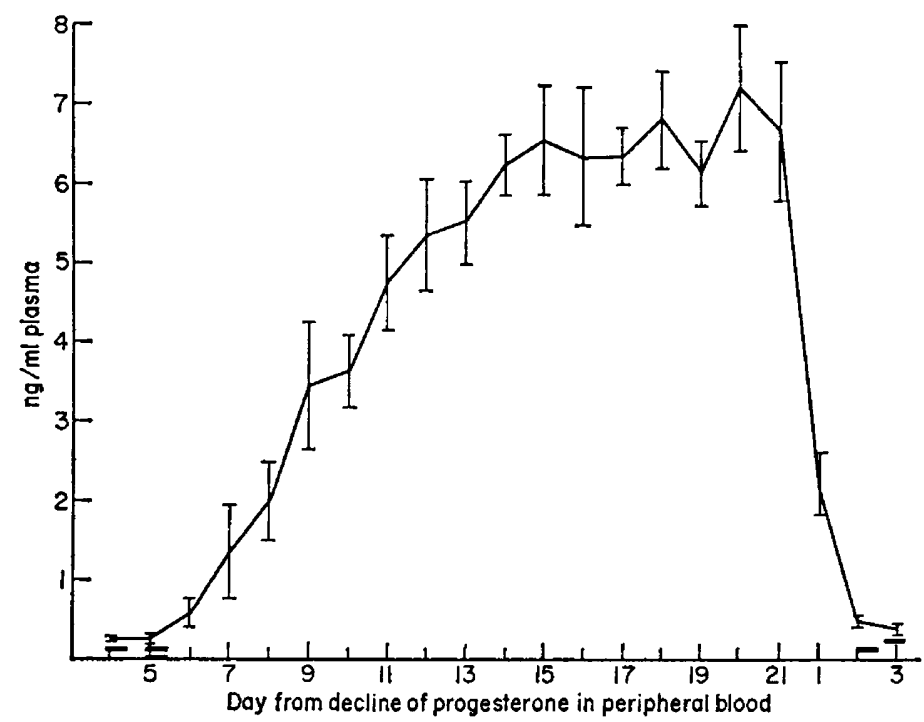

Text-fig. 3. Progesterone concentration in jugular venous plasma from five cows with 21-day oestrous cycles. Data from cows were adjusted so that Day 1 represented the first day progesterone decrease was greater than $50 \%$ from the previous day. Vertical bars represent the SEM; horizontal bars indicate the time of oestrus for individual cows.

Because of these wide individual variations, another method was used for presenting the composite data (Text-fig. 3). The data from each cow (21-day cycles only) were co-ordinated by designating the first day progesterone fell $50 \%$ from the previous day as Day 1 . The decrease in progesterone in the peripheral plasma that occurred towards the end of the cycle is very evident and is representative of what happened in a typical cow. That Text-fig. 3 more closely approximates conditions in each individual cow can be seen by inspecting data shown in Text-fig. 4. Curves for individual cows in general all showed the same cyclic pattern with a precipitous fall in progesterone occurring 1 to 5 days preceding oestrus.

The $95 \%$ confidence interval on any particular day was $\bar{x} \pm 0.4 \mathrm{ng}$ where $\bar{x}$ is the average of two duplicates, $S \bar{x}$ is the estimate of the standard deviation of the mean of two duplicates and $t$ is Student's $t_{0.05}$ associated with 143 degrees of freedom (number of duplicate sets). The precision and accuracy of the technique have been reported (Stabenfeldt $e t$ al., 1969). Known amounts of progesterone $(10,25,100$ and $250 \mathrm{ng} / \mathrm{sample})$ were analysed; accuracy results 
indicated a tendency to overestimate the amount of progesterone present by approximately $5 \%$ with the exception of the $10 \mathrm{ng}$ level where an over-estimation of $13.5 \%$ was made. The precision of these experiments ranged from $2.4 \%$ to $3 \cdot 3 \%$.

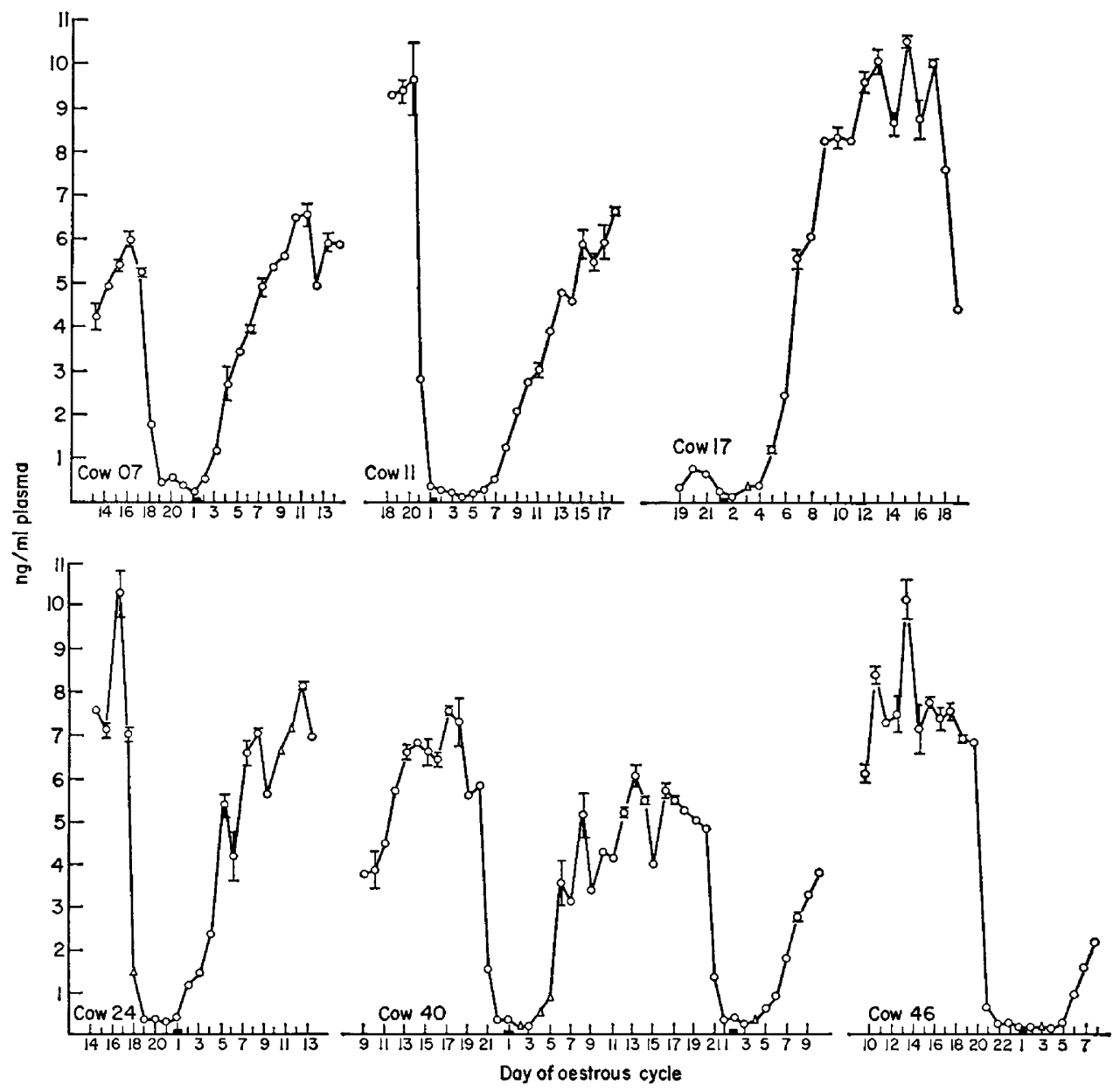

TEXT-FIG. 4. Progesterone concentration in jugular venous plasma of individual cows during the bovine oestrous cycle (oestrus = Day 1). Vertical bars indicate the range of duplicate determinations.

\section{DISGUSSION}

The cyclic pattern of progesterone concentration in jugular plasma found in this study is in agreement with known changes in CL function in the cow that occur during the oestrous cycle. The rapid decline of progesterone in the peripheral plasma of the cow towards the end of the cycle as well as the marked rise in concentration during the time of CL development is strong evidence for suggesting cL function can be monitored in peripheral plasma by progesterone determination. That the plasma progesterone levels would decrease rapidly 
with declining aL function is suggested by the short biological half-life of progesterone $(22.4 \mathrm{~min})$ reported by Imori (1967) in non-pregnant cows during the regressing luteal phase of the cycle. Likewise, McCracken (1963) found the time required for progesterone to decrease to one-half of its original concentration following CL enucleation ranged from 15 to $30 \mathrm{~min}$.

The finding of Schomberg et al. (1967) of an average of 3, 4.8, 9.6 and 1.5 $\mathrm{ng} / \mathrm{ml}$ on Days $6,11,16$ and 21 of the oestrous cycle (oestrus = Day 1) indicated a cyclic pattern of progesterone concentration in the peripheral plasma of the cow. Likewise, Gupta \& Pope (1968) found a cyclic pattern of progesterone in the non-pregnant cow; 7.5 to $10.0 \mathrm{ng} / \mathrm{ml}$ were found during the luteal phase while 1 to $2 \mathrm{ng} / \mathrm{ml}$ were observed for a 4- to 6-day period around the time of ovulation. Earlier, Short $(1957,1961)$ found $4.0 \mathrm{ng}$ progesterone $/ \mathrm{ml}$ $24 \mathrm{hr}$ before ovulation in one cow and 3.8 and $9.4 \mathrm{ng} / \mathrm{ml}$ in two other animals during the luteal phase of the cycle. McCracken (1963) observed an average of $9 \cdot 6$ and $8 \cdot 8 \mathrm{ng} / \mathrm{ml}$ plasma on Day 12 in two cows for two consecutive cycles. The luteal phase levels found in this study are in agreement $(6.6 \mathrm{ng} / \mathrm{ml}$ average; Days 13 to 17). The average levels found at oestrus \pm 3 days $(0.4 \mathrm{ng} / \mathrm{ml})$ are lower than those previously reported.

Dobrowolski, Stupnicka \& Domański (1968) found a cyclic pattern of progesterone in the ovarian venous blood of cows. They found progesterone levels reached a peak on about Day 16 (oestrus = Day 1 ) followed by a decline on Day 17 continuing until ovulation.

A rapid decline in progesterone in peripheral plasma late in the bovine oestrous cycle was indicated by the work of Shemesh, Ayalon \& Lindner (1968). A decline from $4.7 \mathrm{ng} / \mathrm{ml}$ on Day 19 (oestrus = Day 1 ) to $1.5 \mathrm{ng} / \mathrm{ml}$ or less on Day 20 was observed in cows failing to conceive. The average concentration of progesterone (about $4.4 \mathrm{ng} / \mathrm{ml}$ ) found between Days 11 and 19 was lower than found in this study.

In a recent study, Plotka et al. (1967) estimated progesterone in the peripheral plasma of twelve cows on alternate days during the oestrous cycle using the double isotope derivative technique of Woolever \& Goldfien (1963). While the data showed a cyclic pattern of progesterone concentration, the shape of the curve as well as the amount of hormone present differed from the data reported in this study. The sharp decline observed at Day 7 by Plotka et al. (1967) was not observed in the present study; as seen in Text-fig. 1, the rise in progesterone was continuous from Day 3 until about Day 8 with a slower rate of increase until about Day 17.

The progesterone levels reported by Plotka et al. (1967) declined gradually from Day 15 until the next oestrus. In this study, peak progesterone levels were high until at least Day 17; the subsequent decline in concentration was rapid. The levels of progesterone observed by Plotka et al. (1967) were much higher than those found in the current study during the follicular phase (10 ng versus $0.4 \mathrm{ng} / \mathrm{ml}$ plasma); peak luteal levels were about four times higher (25 $\mathrm{ng}$ versus $6.6 \mathrm{ng} / \mathrm{ml}$ plasma). One of the principal problems of the double isotope technique is removal of excess tritiated products. The presence of tritium, other than that associated with progesterone, would result in a quantitative over-estimation of progesterone. While the luteal phase progesterone levels in 
human plasma as estimated by the double isotope technique (Woolever, 1963) were only slightly higher than those determined by the $20 \beta$-hydroxypregn-4en-3-one chloroacetate derivative method (van der Molen \& Groen, 1965) and the competitive protein-binding radio-assay method (Neill, Johansson, Datta \& Knobil, 1967), the follicular phase levels of Woolever (1963) were four times higher. These follicular phase levels were later acknowledged to be due to unrecognized high blank values (Woolever, 1965). High blank values may partially explain the discrepancy between the progesterone data reported herein and those of Plotka et al. (1967).

The follicular phase levels reported here for the cow $(0.4 \mathrm{ng} / \mathrm{ml}$ plasma) are similar to those reported by van der Molen \& Groen (1965) for the follicular phase (Days 1 to 9) in women $(0.5 \mathrm{ng} / \mathrm{ml}$ plasma). Likewise, Neill et al. (1967) found $0.4 \mathrm{ng} / \mathrm{ml}$ plasma in women during the 12 days of the menstrual cycle which preceded $\mathrm{LH}$ release.

Mares, Zimbelman \& Casida (1962) found peak luteal function at Day 16 (oestrus $=1$ ) of the bovine cycle as indicated by peak progesterone concentration in CL. Likewise, Gomes, Estergreen, Frost \& Erb (1963) obtained bovine GL at various times of the cycle with peak luteal progesterone concentration recorded at Day 15; the decrease in progesterone concentration observed on Days 16 and 17 was interpreted as evidence for failing $\mathrm{CL}$ function. In the present study, cows had elevated progesterone levels in the peripheral blood at Days 17 to 20 of the cycle. Because of the relatively short half-life of progesterone, the assumption may be made that these animals had functional CL during this time.

In vitro studies conducted by Armstrong \& Black (1966) showed that the bovine CL may be functional beyond Day 15 . These workers found that the CL could respond directly to an NADPH-generating system or indirectly to luteinizing hormone (LH) by progesterone biosynthesis up to Day 18; LH appeared to stimulate NADPH production by CL. The failure of the GL to synthesize progesterone towards the end of the cycle was thought to be due to an inability of the CL to respond to LH by increased NADPH production and not an inability to respond to NADPH once it was formed.

If peak luteal progesterone concentration does occur at either Day 15 or 16 as reported by Gomes et al. (1963) and Mares et al. (1962), it appears from the data recorded in this study that CL may be able to maintain high levels of progesterone in the blood even though the concentration of hormone in the organ is declining. Staples \& Hansel (1961) reported data that show a base level of $100 \mu \mathrm{g}$ of luteal progesterone may be sufficient for embryo maintenance in heifers although levels two to three times greater have been observed more commonly in normal animals. These observations raise the question of the validity of using hormone concentration in endocrine glands as an absolute indicator of physiological activity. Nalbandov (1966), as well as others, has strongly emphasized the inadequacy of pituitary assays without examination of peripheral or subdural plasma hormone levels. It may be that high CL progesterone content is not an absolute requirement for maintaining plasma levels.

It appears that cows vary considerably as to the time required for follicular development following regression of the cL. This variation may be one reason for 
the lack of precise grouping of oestrus following oestrous synchronization. Likewise, the low conception rate often observed for cows at the first oestrus after synchronization may be a result of the production of psychic oestrus by certain critical levels of oestrogens and progestins without sufficient time lapse for follicle development and maturation.

\section{ACKNOWLEDGMENTS}

The authors appreciate the technical assistance of Dr J. P. Patton, Virginia Buchanan-Smith, Zada Herd and June Patton. We are indebted also to Dr G. R. Waller, Dr E. D. Mitchell and Mr K. F. Kinneberg, Department of Biochemistry, Oklahoma State University, for the mass spectrometer data. Dr R. D. Morrison, Department of Mathematics and Statistics, Oklahoma State University, advised on the statistical analysis. This research was supported by USPHS Grants HD-02053 and HD-00636 and Oklahoma State University Agricultural Experiment Station Project No. 1283.

\section{REFERENGES}

ARMstrong, D. T. \& BLACK, D. L. (1966) Influence of luteinizing hormone on corpus luteum metabolism and progesterone biosynthesis throughout the bovine estrous cycle. Endocrinology, 78, 937.

Dobrowolski, W., Stupnicka, E. \& Domański, E. (1968) Progesterone levels in ovarian venous blood during the oestrous cycle of the cow. F. Reprod. Fert. 15, 409.

Gomes, W. R., Estergreen, V. L., Frost, O. L. \& ERB, R. E. (1963) Progestin levels in jugular and ovarian venous blood, corpora lutea, and ovaries of the nonpregnant bovine. F. Dairy Sci. 46, 553.

Gupta, S. K. \& Pope, G. S. (1968) Variation in the level of progesterone in the systemic plasma of the cow. F. Endocr. 40, xii.

Horning, E. C., Maddock, K. C., Anthony, K. V. \& VandenHeuvel, W. J. A. (1963) Quantitative aspects of gas chromatographic separation in biological studies. Analyt. Chem. 35, 526 .

IMORI, T. (1967) The biological half life of progesterone in the peripheral blood of cows. Jap. F. vet. Sci. 29, 201.

Mares, S. E., Zimbelman, R. G. \& Casida, L. E. (1962) Variation in progesterone content of the bovine corpus luteum of the estrual cycle. $\mathcal{F}$. Anim. Sci. $21,266$.

McCracken, J. A. (1963) Plasma progesterone concentration after removal of the corpus luteum in the cow. Nature, Lond. 198, 507.

Nalbandov, A. V. (1966) Summation of conference proceedings. F. Reprod. Fert., Suppl. 1, 129.

Neill, J. D., Johansson, E. D., Datta, J. K. \& KnobiL, E. (1967) Relationship between the plasma levels of luteinizing hormone and progesterone during the normal menstrual cycle. $\mathcal{F}$. clin. Endocr. Metab. 27, 1167.

Plotka, E. D., Erb, R. E., Callahan, C. J. \& Gomes, W. R. (1967) Levels of progesterone in peripheral blood plasma during the estrous cycle of the bovine. F. Dairy Sci. 50, 1158.

Schomberg, D. W., Coudert, S. P. \& Short, R. V. (1967) Effects of bovine luteinizing hormone and human chorionic gonadotrophin on the bovine corpus luteum in vivo. F. Reprod. Fert. 14, 277.

Shemesh, M., Ayalon, N. \& Lindner, H. R. (1968) Early effect of conceptus on plasma progesterone level in the cow. F. Reprod. Fert. 15, 161.

SHORT, R. V. (1957) Progesterone and related steroids in the blood of domestic animals. In: Hormones in Blood: Ciba Fdn Colloq. Endocr., Vol. II, pp. 362-375. Eds. G. E. W. Wolstenholme and Elaine C. P. Millar. Little, Brown, Boston.

Short, R. V. (1961) Progesterone. In: Hormones in Blood, Vol. I, pp. 379-437. Eds. C. H. Gray and A. L. Bacharach. Academic Press, New York.

StABENFELDT, G. H. (1968a) Studies on progesterone levels in the peripheral blood of cows during the estrous cycle. $\mathrm{Ph} . \mathrm{D}$. thesis, Oklahoma State University.

Stabenfeldt, G. H. (1968b) VIII Biennial symposium on animal reproduction. F. Anim. Sci. 27, Suppl. 1, 209.

Stabenfeldt, G. H., Ewing, L. L. \& McDonald, L. E. (1966) Determination of bovine plasma progesterone using gas-liquid chromatography with electron capture detection. Physiologist, Wash. 9, 293. 
Stabenfeldt, G. H., Ewing, L. L., Patton, J. P. \& McDonald, L. E. (1969) Gas-liquid chromatography for estimation of peripheral plasma progesterone in domestic animals. 7 . Endocr. 44, 23.

Staples, R. E. \& Hansel, W. (1961) Luteal function and embryo survival in the bovine. 7. Dairy Sci. 44, 2040.

van der Molen, H. J. \& Groen, D. (1965) Determination of progesterone in human peripheral blood using gas-liquid chromatography with electron capture detection. 7. clin. Endocr. Metab. 25, 1925.

Woolever, C. A. (1963) Daily plasma progesterone levels during the menstrual cycle. Am. F. Obstet. Gynec. 85, 981 .

Woolever, C. A. (1965) Sodium borotritide as an agent for tritium labeling in the assay of steroid hormones. In: Proceedings of the II Int. Congr. Endocrinology, p. 287. Excerpta Medica Fdn, New York.

Woolever, G. A. \& Goldfien, A. (1963) A double-isotope derivative method for plasma progesterone assay. Int. . appl. Radiat. Isotopes, 14, 163. 